\title{
EXTRAÇÃO, CARACTERIZAÇÃo QUÍMICA E ATIVIDADE ANTIFÚNGICA DE ÓLEO ESSENCIAL Syzygium aromaticum (CRAVO DA ÍNDIA)*
}

\author{
EXTRACTION, CHEMICAL CHARACTERIZATION AND ANTIFUNGAL ACTIVITY OF ES- \\ SENTIAL OIL Syzygium aromaticum (CLOVE)
}

\author{
EXTRACCIÓN, CARACTERIZACIÓN QUÍMICA Y ACTIVIDAD ANTIFÚNGICA DE ACEITE \\ ESENCIAL Syzygium aromaticum (clavo)
}

Vanessa Louzeiro Ascenção Victor Elias Mouchrek Filho

\begin{abstract}
Resumo: A espécie vegetal Syzygium aromaticum, conhecida popularmente como cravo-da-índia, pertence à família das Mirtaceae e é explorada principalmente para extração industrial do óleo essencial obtido a partir dos botões florais, folhas e outras partes. Seu fruto contém um óleo essencial de grande valor econômico no mercado, devido ao elevado teor de eugenol (seu composto majoritário) o qual é largamente usado nas indústrias químicas e farmacêuticas. Neste trabalho, promoveu-se a extração do óleo essencial dos botões florais secos de Syzygium aromaticum através do método da hidrodestilação, utilizando um sistema de Clevenger modificado. Além das constantes físicas densidade, índice de refração, solubilidade, cor e aparência, foi possível, através da técnica de cromatografia gasosa/espectrometria de massas, identificar os componentes do óleo essencial e o eugenol como constituinte majoritário do óleo essencial de Syzygium aromaticum, com 52,53\%. Ao óleo essencial deu-se a aplicação fungicida, em que foi estudado o efeito antifúngico do óleo essencial de cravo da índia frente aos fungos $F$. oxysporum f. sp. vasinfectum, F. oxysporum f. sp. passiflorae, F. oxysporum f. sp. lycopercisi, F. oxysporum f. sp. Tracheiphilum. Obtiveram-se ótimos resultados, já que a inibição de crescimento fúngico chegou a ser total em dois dos fungos estudados e entre $85 \%$ e $90 \%$ nos outros dois. Esse efeito justifica-se em razão do eugenol (componente majoritário do óleo) ter ação antifúngica comprovada.
\end{abstract}

Palavras-chave: Óleo essencial. Cravo-da-índia. Atividade antifúngica.

\begin{abstract}
The plant species Syzygium aromaticum, popularly known as clove, belongs to the family of Mirtaceae and operated primarily for industrial extraction of essential oil obtained from the flower buds, leaves and other parts. Its fruit contains an essential oil of great economic value in the market due to the high content of eugenol (its major compound) which is widely used in chemical and pharmaceutical industries. In this paper, we promoted the extraction of essential oil from dried flower buds of Syzygium aromaticum through the method of hydrodistillation using a modified Clevenger system. Besides the physical constants density, refractive index, solubility, color and appearance, was possible using the technique of gas chromatography / mass spectrometry to identify the components of the essential oil and eugenol as major constituent of the essential oil of Syzygium aromaticum, with $52.53 \%$. When essential oil gave up the fungicide application, in which we studied the antifungal effect of the essential oil of clove front fungi F. oxysporum f. sp. vasinfectum, F. oxysporum f. sp. passiflorae, F. oxysporum f. sp. lycopercisi, F. oxysporum $f$. sp. Tracheiphilum. There were obtained excellent results since fungal growth inhibition became total of two fungi studied and between $85 \%$ and $90 \%$ in the other two. This effect excused on account of eugenol (major component of the oil) have proven antifungal effect.
\end{abstract}

Keywords: Essential oil. Clove. Antifungal activity.

Resumen: La especie vegetal Syzygium aromaticum, popularmente conocida como clavo de olor, pertenece a la familia Mirtaceae y es explotada principalmente para la extracción industrial de aceite esencial obtenido de los capullos de las flores, las hojas y otras partes. Su fruto contiene un aceite esencial de gran valor económico en el mercado debido al alto contenido de eugenol (su compuesto principal) que es ampliamente utilizado en la industria química y farmacéutica. En este trabajo, hemos promovido la extracción de aceite esencial de capullos secos de Syzygium aromaticum a través del método de hidrodestilación utilizando un sistema Clevenger modificado. Además de las constantes físicas, densidad, índice de refracción, solubilidad, color y apariencia, fue posible, usando la técnica de cromatografía de gases / espectrometría de masas identificar los componentes del aceite esencial y el eugenol como componente principal del aceite esencial de Syzygium aromaticum, con $52,53 \%$. Al aceite esencial se le atribuyó la acitividad de fungicida, en el que se estudió el efecto antifúngico del aceite esencial de clavo frente a hongos $F$. oxysporum $f$. sp. vasinfectum, F. oxysporum $f$. sp. passiflorae, F. oxysporum $f$. sp. lycopercisi, F. oxysporum f. sp. Tracheiphilum. Se obtuvieron excelentes resultados ya que la inhibición del crecimiento fúngico fue total en dos de los hongos estudiados y entre $85 \%$ y $90 \%$ en los otros dos. Este efecto es explicado por cuenta de eugenol (componente principal del aceite) que tiene un efecto antifúngico comprobado.

Palabras clave: Aceite esencial. Clavo de olor. La actividad antifúngica.

Trabalho premiado durante o XXIV Encontro do SEMIC, realizado na UFMA entre os dias 05 a 08 de novembro de 2012. *Artigo recebido em dezembro 2012

Aprovado em fevereiro 2013 


\section{INTRODUÇÃO}

\subsection{Plantas medicinais}

Há milhões de anos as plantas são utilizadas pelos homens, que perceberam e continuam a descobrir a importância que estas possuem para o bem estar humano. Esta interação se traduz na religiosidade, modo de vida, trabalho, no trato com a saúde, conforme a compreensão dos grupos culturais que, desde antigamente, até os dias atuais praticam alguns dos conhecimentos repassados através de gerações (VICTÓRIO, 2008).

Pode ser considerada Planta Medicinal qualquer planta que possua em um ou mais dos seus órgãos (folha, caule, fruto, raiz etc) substâncias biologicamente ativas (princípios ativos), com propriedades terapêuticas ou que sirvam como precursoras da síntese de fármacos (AGÊNCIA NACIONAL DE VIGILÂNCIA SANITÁRIA, 2004).

A questão da saúde e segurança alimentar vem sendo preocupações constantes entre a população nos últimos anos. Em face disso, há uma tendência da substituição de fármacos sintéticos e conservantes de alimentos industrializados por substâncias naturais, em especial aquelas extraídas de plantas e condimentos, tais como o óleo essencial (ALARCÓN, 2007; BURT, 2004).

Há mais de seis mil anos, os egípcios já conheciam o poder das substâncias químicas aromáticas e sua influência sobre a saúde do corpo, da mente e do espírito. Estas substâncias, chamadas de óleos essenciais, são encontradas em inúmeras plantas aromáticas, sob a forma de pequenas gotas entre as células, onde agem como hormônios, reguladores e catalisadores (LAVABRE, 1992).

Os óleos essenciais estão entre os constituintes ativos das plantas medicinais, os quais exercem funções primordiais à manutenção da espécie vegetal, tais como a de defesa contra predadores e patógenos, bem como atrativo de polinizadores, aroma, entre outras (RAVEN; VERT; ELICHHORN, 2001).

\section{2 Óleos essenciais}

Os óleos essenciais são compostos voláteis retirados das plantas ou especiarias. A sua composição química depende de vários fatores, principalmente da origem da planta. Por isso, cada óleo tem uma composição química específica. O óleo essencial é composto por mais de 300 componentes químicos diferentes, o que faz dele um produto tão valorizado (WOLFFENBÜTTEL, 2007).

São compostos orgânicos voláteis extraídos das sementes, as raízes, as madeiras, as cascas, as folhas e as flores das plantas (MOUCHREK FILHO, 2000).

Os óleos essenciais são misturas de diversas substâncias químicas produzidas pelas plantas aromáticas, entre elas os terpenos e compostos terpênicos, sesquiterpenos e compostos sesquiterpênicos e derivados de fenilpropano (LAVABRE, 1992). Terpenos e sesquiterpenos são hidrocarbonetos constituídos por dez e quinze átomos de carbono, respectivamente, sendo ambos obtidos pela mesma via biossintética. Os diterpenos - moléculas com vinte átomos de carbono - são dificilmente encontrados nos óleos essenciais. As plantas também sintetizam moléculas com trinta ou quarenta átomos de carbono, mas estes não são óleos essenciais. Os óleos essenciais são relativamente fluidos, mas alguns são sólidos a temperatura ambiente. Diferenciam-se dos óleos graxos por sua natureza altamente volátil, sendo insolúveis em água, fracamente solúveis em ácido acético, muito solúveis em álcool, podendo ser misturados com óleos vegetais, gorduras e ceras. Outros grupamentos funcionais, como cetonas, aldeídos, ésteres, álcoois terpênicos, fenóis e cineol também podem ser encontrados nos óleos essenciais. (GRAMOLELLI, 2006).

Flores, folhas, cascas, rizomas e frutos são matérias-primas para sua produção, a exemplo dos óleos essenciais de rosas, eucalipto, canela, gengibre e laranja, respectivamente. Possuem grande aplicação na perfumaria, cosmética, alimentos e como coadjuvantes em medicamentos. São empregados principalmente como aromas, fragrâncias, fixadores de fragrâncias, em composições farmacêuticas e orais e comercializados na sua forma bruta ou beneficiada, fornecendo substâncias purificadas como o limoneno, citral, citronelal, eugenol, mentol e safrol. (CRAVEIRO, QUEIROZ, 1993; SILVA-SANTOS et al., 2006).

Os óleos essenciais apresentam diferentes propriedades biológicas, como a ação larvicida, atividade antioxidante, ação analgésica e antiinflamatória, fungicida, e atividade antitumoral.

\subsection{Cravo-da-índia}

O cravo-da-índia, em séculos atrás, era tão disputado que países europeus, como Holanda e França, costumavam entrar em disputas comerciais acirradas por sua posse. No começo do século XIX, plantações de cravos-da-índia foram levadas a países tropicais, dentre eles o Brasil. (MANON, 2002).

O craveiro-da-índia é uma árvore de ciclo perene, que cresce a uma altura que varia de 10 a 12 metros, possui folhas ovais grandes e flores de cor vermelha que se apresentam em numerosos grupos de cachos terminais (ALMA et al., 2007). Essa planta vive por cerca de 100 anos e há alguns recordes de árvores atingindo 150 anos (OLIVEIRA et al., 2008).

$\mathrm{O}$ cravo pertence à família Myrtaceae. As espécies desta família são particularmente 
ricas em óleos essenciais. A família é constituída de 140 gêneros e aproximadamente 3000 espécies. (CERQUEIRA et al., 2009).

A espécie é explorada principalmente para extração industrial do óleo essencial obtido a partir dos botões florais, folhas e outras partes (LORENZI; MATOS, 2002).

Muito conhecido por seu uso como condimento na culinária, suas propriedades anestésicas e anti-sépticas também são difundidas. (MANON, 2002).

O óleo de cravo-da-índia é um anestésico eficiente e a ação da mastigar um cravo pode eliminar uma dor bucal e também higienizá-la. Os chás são indicados contra náuseas e indigestões. Como anti-séptico, o uso de tinturas pode tratar infecções por fungos e outros microrganismos. (MANON, 2002).

O óleo essencial do botão de cravo é pouco produzido, embora sua procura seja grande. O botão contém $17 \%$ de óleo essencial e o talo que o acompanha contém 4,5-6 \%. O óleo pode conter até $90 \%$ de Eugenol, tendo como segundo maior constituinte o Cariofileno. (CRAVEIRO; QUEIROZ, 1993).

O preço e o teor de Eugenol colocam este óleo como uma opção econômica, como matéria prima para produtos de maior valor comercial. (CRAVEIRO; QUEIROZ, 1993).

O Eugenol é um líquido fracamente amarelado, que escurece ao ar, com aroma de cravo, e com sabor ardente e picante. Sua fórmula molecular é $\mathrm{C} 10 \mathrm{H} 12 \mathrm{O} 2$ e massa molar $164 \mathrm{~g} /$ mol (MOUCHREK FILHO, 2000). Este é muito usado como flavorizante (CRAVEIRO, 1981), antioxidante (FAJARDO, 1997), antiespasmódico (MOUCHREK FILHO, 2000), anti-séptico, agente antimicrobiano, agente bactericida, fungicida, inibidor inflamatório (OMS, 2010), antialérgico, na composição de cosméticos assim como no tratamento da AIDS (ATRASO, 2010).

\subsection{Fungos fitopatogênicos}

\subsubsection{O gênero Fusarium}

Os fungos pertencentes ao gênero Fusarium são patógenos de planta e também contaminantes de alimentos, são responsáveis por numerosas micoses em animais e humanos. Como fitopatógeno de planta atua causando murcha através do micélio que invade o tecido vascular da planta e junto com os conídios bloqueiam o xilema, evitando, desse modo, o movimento de água. Quando esse bloqueio é considerável, ocorre a murcha (MONTEIRO, 2004). A maioria das murchas é causada pela espécie Fusarium oxysporum Schlecht, que possui uma gama expressiva de hospedeiros, afetando as plantas através de diversas formas especiais, com base na especificidade do hospedeiro. (AGRIOS, 2005).

A espécie Fusarium oxysporum Schlecht é caracterizada pelo crescimento rápido, colônias com coloração pálida ou colorida (violeta à púrpura ou creme à laranja), com micélio aéreo e difuso (DOMSH et al., 1980).
A maioria das espécies de Fusarium é composta de fungos habitantes do solo, com distribuição cosmopolita e ativo na decomposição de substratos celulósicos das plantas, sendo que alguns isolados são parasitas das plantas (GODOY; COLOMBO, 2004).

Segundo Alexoupoulos et al. (1996), a espécie $F$. oxysporum possui inúmeras formas especiais, que são responsáveis por causar doenças denominadas fusariose em vários hospedeiros específicos, dos quais destacam-se:

a) F. oxysporum f. sp. lycopersicon Sacc. Snyder \& Hansen - hospedeiro do tomate (Lycopersicum esculentum Mill);

b) F. oxysporum f. sp. tracheiphilum (E. F. Smith) W. C. Snyder \& H. N. Hansen - hospedeiro do feijão-caupi (Vigna ungiculata (L.) Walp);

c) F. oxysporum f. sp. passiflorae W. L. Gordon - hospedeiro do maracujá (Passiflora edulis Sims);

d) F. oxysporum f. sp. vasinfectum (Atk) Snyder \& Hansen - hospedeiro do quiabo (Abelmoschus esculentus (L.) Moench).

\subsection{Atividade antifúngica}

Quanto ao tratamento de doenças provocadas por fungos, verifica-se que a terapêutica convencional é limitada, normalmente em função da baixa amplitude das drogas antimicrobianas, custo elevado do tratamento e sua longa duração. Dessa forma, justifica-se a busca e o uso de novas substâncias e terapias alternativas, possibilitando a inclusão de produtos naturais, como os óleos essenciais, como agentes com potencial ação antifúngica (SILVA et al., 2008).

\section{METODOLOGIA}

\subsection{Obtenção das amostras de cravo-da- índia}

Os botões florais de cravo-da-índia foram obtidos em feira livre de São Luís no período de outubro de 2011.

\subsection{Extração do óleo essencial}

O óleo essencial de Syzygium aromaticum foi extraído em sistema extrator Clevenger, acoplado ao um balão volumétrico de $6000 \mathrm{~mL}$ e, como fonte de calor, uma manta de aquecimento.

Na extração do óleo essencial, pesaramse aproximadamente 400 gramas dos botões florais secos do cravo da índia e adicionaramse $4000 \mathrm{~mL}$ de água destilada. Em seguida, ajustou-se a temperatura da manta elétrica em $100^{\circ} \mathrm{C}$. Após 4 horas de destilação, recolheuse o óleo essencial. O óleo foi seco por meio de percolação com Na2SO4 anidro. Essas etapas foram realizadas em triplicata e as amostras foram armazenadas em recipientes de vidro 
sobre refrigeração para evitar possíveis perdas de constituintes voláteis.

O rendimento da extração foi calculado na relação volume/massa e massa/massa, observando o volume obtido no próprio sistema de extração.

\subsection{Caracterização físico-química do óleo essencial}

As propriedades físico-químicas do óleo essencial determinadas foram: densidade, solubilidade em etanol a $90 \% \mathrm{v} / \mathrm{v}$, índice de refração, cor e aparência.

\section{Densidade}

Para o cálculo da densidade, utilizouse um picnômetro de $1,0 \mathrm{~mL}$, previamente seco, tarado e aferido, onde se adicionaram e pesaram as amostras do óleo essencial $\left(25^{\circ} \mathrm{C}\right)$.

II. Solubilidade em etanol a $90 \% \mathrm{v} / \mathrm{v}$

$\mathrm{Na}$ determinação da solubilidade, utilizouse uma solução de etanol/água a $90 \%(\mathrm{v} / \mathrm{v})$, mantendo-se constante o volume de óleo e adicionando-se proporcionalmente volumes diferentes e crescentes da solução alcoólica até se atingir a completa solubilização.

\section{III. Índice de refração}

Para a determinação do índice de refração, utilizaram-se pipetas de Pasteur para adicionar as amostras dos óleos diretamente sobre o prisma de Flint do refratômetro, à temperatura de $25^{\circ} \mathrm{C}$; fazendo-se então as leituras.

\section{Cor e aparência}

A técnica utilizada foi visual, onde, sob um fundo branco, se comparou a cor do óleo essencial com cores conhecidas e para a aparência se fez uma inspeção do óleo no que diz respeito a sua transparência ou limpidez.

\subsection{Análise química do óleo essencial}

A análise físico-quimica do óleo essencial de Syzygium aromaticum foi feita por cromatografia gasosa acoplada à espectroscopia de massas (CG-EM).

Para a determinação química do óleo, foi utilizada a análise por meio da cromatografia gasosa contendo uma coluna capilar HP-5MS, 5\% difenil, 95\% dimetil polisiloxano (30 m x 0,25 mm; 0,25 $\mu \mathrm{m}$ de espessura de filme) com fase estacionária. O cromatógrafo do modelo QP-500 fabricado pela Shimadzu tendo hélio como gás de arraste, com fluxo na coluna de $1 \mathrm{~mL} . \mathrm{min}-1$.

Para as análises, foram injetadas alíquotas de 0,3 $\mu \mathrm{L}$ da amostra diluída (1,0 mg do óleo em $1000 \mu \mathrm{L}$ de diclorometano com pureza de 99,9\%), fixando-se as seguintes condições: temperatura do injetor em $280{ }^{\circ} \mathrm{C}$; split de 1:10; programação de temperatura do forno de $40{ }^{\circ} \mathrm{C}$ (5,0 min.) a $240{ }^{\circ} \mathrm{C}$ ( com taxa de aquecimento de $4^{\circ} \mathrm{C} / \mathrm{min}$.) e de 240 a $300{ }^{\circ} \mathrm{C}$ (com taxa de aquecimento de $\left.8^{\circ} \mathrm{C} / \mathrm{min} ., 7,5 \mathrm{~min}\right)$.

No Espectrômetro de Massas do tipo quadrupolo linear o modo de varredura foi de 0,5 seg/scan, a faixa de varredura variou de 40 a 500 daltons cada uma, a linha de transferência foi de $280^{\circ} \mathrm{C}$ e o filamento desligado em 0,0 a 4,0 min.

Os constituintes foram identificados por comparação dos resultados obtidos (índices de retenção e espectros de massa) com os dados da espectroteca do aparelho e literatura.

\subsection{Avaliação da atividade antifúngica}

Os diferentes óleos essenciais foram adicionados ao meio BDA fundente (Batata-Dextrose-Ágar), aproximadamente $45^{\circ} \mathrm{C}$, na presen-

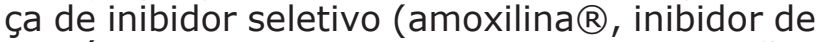
bactérias) a fim de se obter as concentrações de 1,$25 ; 2,5 ; 3,75$; e $5 \%$, em que cada concentração representou um tratamento. Placas de Petri somente com meio BDA, sem adição de óleos essenciais foram como testemunha.

Discos de $5 \mathrm{~mm}$ com crescimento fúngico de $F$. oxysporum f. sp. vasinfectum, $F$. oxysporum f. sp. passiflorae, $F$. oxysporum f. sp. lycopercisi, F. oxysporum f. sp. tracheiphilum, cultivados em meio BDA, durante 8 dias, foi repicados para o centro das Placas de Petri, contendo respectivas concentrações dos óleos essenciais, incubadas em estufa de fotoperíodo (BOD) a temperatura $28^{\circ} \pm 2^{\circ} \mathrm{C}$ sob o regime de fotoperíodo de $12 \mathrm{~h}$ por um período de 7 dias.

A avaliação do crescimento micelial foi feita pela a medição do crescimento radial da colônia em dois eixos ortogonais, e posteriormente será calculada a média. A avaliação será realizada quando a testemunha cobrir totalmente a placa de Petri. As médias serão calculadas pela percentagem de inibição do crescimento micelial (PIC), segundo Edginton et al. A expressão que determina o cálculo do $\mathrm{PIC}=$ (cresc. Testemunha - cresc. Tratamento/ cresc. Testemunha) x 100 .

A avaliação do efeito fungicida dos óleos essenciais foi verificada, retirando-se discos de micélio dos tratamentos onde não houver crescimento fúngico e transferindo-os para placas de Petri contendo meio BDA sem adição de óleos essenciais.

\section{RESULTADOS E DISCUSSÕES}

\subsection{Propriedades físico-químicas}

As características físico-químicas do óleo essencial de cravo-da-índia estão destacadas na tabela 1 .

O rendimento da extração foi calculado diante da quantidade de óleo que se obteve a partir de uma determinada massa vegetal. Nesse experimento a densidade do óleo foi determinada em $0,973 \mathrm{gmL}^{-1}$, rendimento $(\% \mathrm{~m} / \mathrm{m})$ foi de $3,54 \%$ e o rendimento $(\% \mathrm{v} / \mathrm{m})$ foi de $3,63 \%$.

Comparando resultados, viu-se que Silvestri et al. (2010) encontraram rendimento 
de $1,87 \%(\mathrm{v} / \mathrm{m})$, já Lee e Shibamoto (2001) e Raina et al. (2001) obtiveram rendimentos de $2,75 \%(\mathrm{~m} / \mathrm{m})$ e $4,8 \%(\mathrm{v} / \mathrm{m})$ respectivamente, valores próximos ao encontrado aqui. Todavia, há diferenças significativas ao comparar valores de outros trabalhos, como o encontrado por Wenqiang et al. (2007), Makhaik, Naik e Tewary (2005) e Oliveira (2009), que apresentam respectivamente rendimento de $10,1 \%, 15,1 \%$ e 15,4\% de óleo essencial no cravo-da-índia. Segundo (SIMÕES et al., 2007), a composição do óleo essencial de uma planta é determinada geneticamente, sendo, geralmente, específica para um determinado órgão e característica para o seu desenvolvimento, mas as condições ambientais são capazes de causar variações significativas.

Tabela 1 - Propriedades físico-químicas do óleo essencial de cravo-da-índia

\begin{tabular}{c|c}
\hline $\begin{array}{c}\text { Parâmetros } \\
\text { físicos-químicos }\end{array}$ & $\begin{array}{c}\text { Óleo de Syzygium } \\
\text { aromaticum }\end{array}$ \\
\hline Densidade $\left(\mathrm{g} \mathrm{mL}^{-1}\right)$ & 0,973 \\
\hline Solubilidade em etanol a $(90 \%)$ & $1: 2$ \\
\hline Índice de refração $\left(\mathrm{N}_{\mathrm{D}} 25^{\circ}\right)$ & 1,526 \\
\hline Cor & Transparente \\
\hline Aparência & Límpido \\
\hline Odor & Característico \\
\hline Rendimento $(\% \mathrm{~m} / \mathrm{m})$ & 3,54 \\
\hline
\end{tabular}

Fonte: Elaborado pelos autores

\subsection{Caracterização química - análise por cromatografia gasosa/ espectrometria de massas}

Utilizando-se de cromatografia gasosa acoplada à espectrometria de massas foi possível separar e identificar cinco constituintes do óleo essencial, os quais são apresentados na figura 1 , seguindo a ordem de eluição.

Figura 1 - Cromatograma do óleo essencial de Syzygium aromaticum

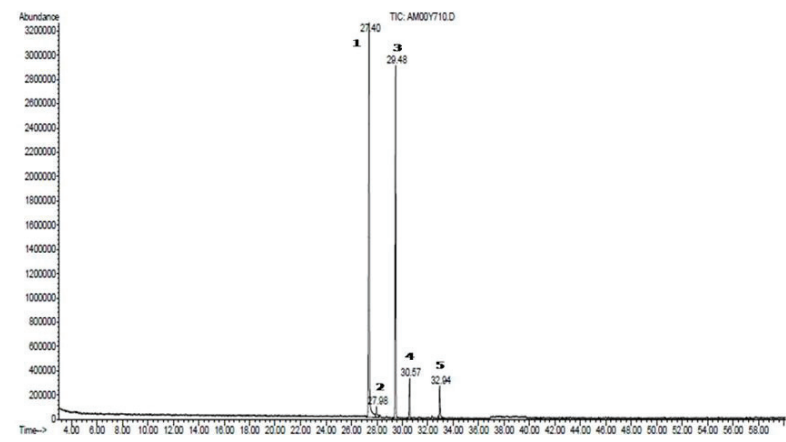

Fonte: Central analítica da USP São Carlos

O pico mais intenso apresentado é o pico 1 , com tempo de retenção de 27,40 min, correspondente ao Eugenol. Os demais picos mostrados correspondem a: copaeno (pico 2), cario- fileno (pico 3), humuleno (pico 4) e acetato de eugenila (pico 5), com os seguintes tempos de retenção, respectivamente: 27,99 $\min , 29,47$ $\min , 30,57 \mathrm{~min}$ e $32,94 \mathrm{~min}$.

Na tabela 2 são apresentados os compostos presentes no óleo juntamente com seus teores.

Tabela 2 - Composição química do óleo essencial de Syzygium aromaticum

\begin{tabular}{c|c|c|c}
\hline Pico & $\operatorname{Tr}(\min )$ & $\begin{array}{c}\text { Substância } \\
\text { identificada }\end{array}$ & Teor (\%) \\
\hline 1 & 27,40 & Eugenol & 52,53 \\
\hline 2 & 27,99 & Copaeno & 2,05 \\
\hline 3 & 29,47 & Cariofileno & 37,25 \\
\hline 4 & 30,57 & Humuleno & 4,11 \\
\hline 5 & 32,94 & Acetato de eugenila & 4,05 \\
\hline
\end{tabular}

Fonte: Elaborado pelos autores

$\mathrm{O}$ alto teor relacionado ao pico 1 do cromatograma $(52,53 \%)$ confirma o eugenol como o componente majoritário do óleo essencial, seguido pelo cariofileno (pico 3 ) com 37,25\%.

Porém, o percentual encontrado do eugenol difere de alguns autores como Costa et al. (2011) que encontraram em suas análises um percentual de eugenol de $83,6 \%$. E também Oliveira et al. (2009) que encontrou um percentual próximo para o eugenol, $88,38 \%$.

\subsection{Atividade antifúngica}

Os resultados observados mostram que o óleo essencial do cravo da índia na concentração de $1 \mu \mathrm{L} / \mathrm{mL}$ em meio BDA foi eficiente no controle do crescimento micelial dos quatro patógenos estudados, variando entre $85,65 \%$ e $100 \%$ de inibição.

Tabela 3 - Efeito do óleo essencial de S. aromaticum sobre o crescimento micelial de diferentes espécies de Fusarium em meio BDA por 7 dias de incubação a $25 \pm 2{ }^{\circ} \mathrm{C}$

\begin{tabular}{c|c|c|c}
\hline \multirow{2}{*}{ Espécies } & \multicolumn{2}{|c|}{$\begin{array}{c}\text { Diâmetro das } \\
\text { Colônias }\end{array}$} & \multirow{2}{*}{$\begin{array}{c}\text { PIC } \\
(\%)\end{array}$} \\
\cline { 2 - 3 } & $\begin{array}{c}\text { Com } \\
\text { Óleo }\end{array}$ & Sem Óleo & \\
\hline $\begin{array}{c}\text { F. oxysporum f. sp. } \\
\text { Tracheiphilum }\end{array}$ & 0 & 7,85 & 100 \\
\hline $\begin{array}{c}\text { F. oxysporum f. sp. } \\
\text { Passiflorae }\end{array}$ & 0,96 & 6,69 & 85,65 \\
\hline $\begin{array}{c}\text { F. oxysporum f. sp. } \\
\text { Lycopersici }\end{array}$ & 0,99 & 7,88 & 87,44 \\
\hline $\begin{array}{c}\text { F. subglutinans f.sp. } \\
\text { vasinfectum }\end{array}$ & 0 & 7,39 & 100 \\
\hline
\end{tabular}

Fonte: Elaborado pelos autores

Os testes com os fungos Fusarium oxysporum f. sp. Tracheiphilum e Fusarium oxysporum 
f. sp. Vasinfectum foram os mais eficazes, tendo como percentual de inibição do crescimento (PIC) igual a $100 \%$. Já com os fungos Fusarium oxysporum f. sp. Passiflorae e Fusarium oxysporum f. sp. lycopersici o óleo apresentou uma inibição de crescimento micelial de $85,65 \%$ e $87,44 \%$, respectivamente, ao fim do experimento.

A inibição do crescimento dos fungos foi significativa, comprovando a atividade antifúngica do óleo essencial. A justificativa para esse efeito está no composto majortário do óleo, o eugenol.

Costa et al. (2011) também verificara inibição total no crescimento de fungos Fusarium oxysporum na concentração de óleo S. aromaticum $0,15 \%$. E justificam esse efeito pela presença do componente majoritário do óleo essencial, o eugenol, que apresenta atividade antifúngica comprovada.

Em Santos et al. (2007), os resultados para análise antifúngica do óleo de cravo da índia são também completamente satisfatórios. Na concentração de $100 p p m$ a inibição foi de $66,57 \%$ e na concentração de 500ppm foi de $100 \%$ para Fusarium oxysporum.

\section{CONSIDERAÇÕES FINAIS}

Os resultados obtidos durante esse trabalho mostraram a eficiência das técnicas e métodos utilizados, como o sistema Clevenger para extração do óleo e o CG-EM para caracterização química do óleo essencial de cravo-da-índia.

Foi possível identificar cinco componentes do óleo essencial, além de quantificá-los. Evidenciando como composto majoritário o eugenol (teor de 52,53\%), o que está de acordo com a literatura.

Obteve-se um rendimento do óleo essencial, a partir de botões florais secos, considerado bom para um processo de hidrodestilação, 3,54\% (m/m).

Todos os parâmetros físico-químicos avaliados apresentaram resultados satisfatórios, demonstrando a qualidade do óleo essencial.

A atividade antifúngica do óleo essencial de Syzygium aromaticum nas espécies Fusarium oxysporum f. sp. Tracheiphilum, Fusarium oxysporum f. sp. Passiflorae, Fusarium oxysporum f.sp. lycopersici, Fusarium oxysporum $f$. sp. vasinfectum mostrou-se altamente eficaz, com uma inibição de $100 \%$, 85,65\%, $87,44 \%$ e $100 \%$, respectivamente. Devido ao seu composto majoritário, o eugenol.

O óleo essencial de Syzygium aromaticum na concentração de $1 \mu \mathrm{l} / \mathrm{mL}$ agiu como um potente fungicida no combate a fungos prejudiciais às culturas do feijão-caupi, maracujazeiro, tomateiro e quiabeiro, o que permite recomendar o seu uso como forma biodegradável de se combater fungos fitopatogênicos.

Pesquisas adicionais são necessárias para que possa se estender a ação frente antifúngica do óleo essencial de Syzygium aromaticum frente a outros fungos.

\section{REFERÊNCIAS}

\section{AGÊNCIA NACIONAL DE VIGILÂNCIA}

SANITÁRIA. Resolução RDC n 48, de 16 de março de 2004. Dispõe sobre o registro de medicamentos fitoterápicos. Disponível em: <http:www.anvisa.gov.br/medicamentos/ fitoterapicos/registro_fitoterapicos.pdf $>$. Acesso em: 6 mar. $2 \overline{0} 08$.

AGRIOS, G. N. Plant diseases caused by nematodes. In: AGRIOS, G. N. Plant Pathology. 5. ed. London: [s.n.], 2005. p.825-874.

ALARCÓN, M. M. V. Efeito inibitório dos óleos essências no crescimento de Escherichia coli e Staphylococcus aureus em queijo ricota. 2007. 56f. Dissertação (Microbiologia em Agrícola) - Universidade Federal de Lavras, Lavras, 2007.

ALEXOUPOULOS, C.J.; MINIS, C.W.; BLACKWELL, M. Introductory mycology. 4. ed. New York: Jonh Wiley, 1996. 868p.

ALMA, M. H. et al. Chemical composition and content os essential oil from the bud of cultivated Turkish clove (Syzygium aromaticum L.). BioResources, v. 2, n. 2, p. 265-269, 2007.

ATRASO. Disponível em: <http:www. globorural.globo.com/edic/185/rep_tradicao9. htlm>. Acesso em: 10 maio de 2012.

BURT, S. Essential oils: their antibacterial properties and potential applications in foods-a review. International Journal of Food Microbiology, v. 94, p. 223- 253, 2004.

CERQUEIRA, M. D. et al. Variação sazonal da composição do óleo essencial de Myrcia salzmannii Berg. (Myrtaceae). Quim. Nova, v. 32, n. 6, p. 1544-1548, 2009.

COSTA, A.R.T et al. Ação do óleo essencial de Syzygium aromaticum (L.) Merr. \& L.M.Perry sobre as hifas de alguns fungos fitopatogênicos. Rev. Bras. Plantas Med. 2011, v. 13, n. 2, p. 240-245, 2011.

Disponível em: <http://www.scielo.br/pdf/ rbpm/v13n2/v13n2a18.pdf>. Acesso em: 16 maio 2012.

CRAVEIRO, A. A. et al. Óleos essenciais de plantas do nordeste. Fortaleza: EUFC, 1981. $210 \mathrm{p}$.

CRAVEIRO, A. A.; Queiroz, D. C. Óleos essenciais e química fina. Quim. Nova, 1993. p. 16-224.

DOMSCH, K.H. ; GAMS, W.; ANDERSON, T.H. Compendium of soil fungi. New York: Academic Press, 1980.

FAJARDO, G. et al. Comparative study of the oil and supercritical CO2 extract of Mexican pimento (Pimenta dioica Merrill). J. Essent. Oil Res., v. 9. n. 2, p. 181-185, 1997. 
GOBBO-NETO, L.; LOPES, N. P. Plantas medicinais: fatores de influência no conteúdo de metabólitos secundários. Quim. Nova, v. 30, n. 2, p. 374-381, 2007.

GODOY, P.; COLOMBO, A.L. Biologia e relevância clínica do gênero Fusarium spp. Prática Hospitalar, v. 34, p. 136-140, 2004.

GRAMOLELLI, Flávio Júnior et al. Extração de óleos essenciais e verificação da atividade antifúngica. Argumento, ano VIII, n. 14. maio 2006.

LAVABRE, M. Aromaterapia: a cura pelos óleos essenciais. Rio de Janeiro: Record, 1992.

LEE, K. G.; SHIBAMOTO, T. Antioxidant property of aroma extract isolated from clove buds [Syzygium aromaticum (L.) Merr. et Perry]. Food Chemistry, v. 74, p. 443-448, 2001.

LORENZI, H.; MATOS, F.J.A. Plantas

medicinais do Brasil: nativas e exóticas. Nova Odessa: Instituto Plantarum, 2002. 512p.

MAKHAIK, M.; NAIK, S. N.; TEWARY, D. K. Evaluation of anti-mosquito properties of essential oils. Journal of scientific \& industrial research, v. 64, p. 129-133, 2005.

MANON, Iahel. Canela-da-índia e cravo-daíndia. Revista Educação Ambiental em Ação, ano I, n. 2. set. 2002.

MARTINS, Mayra Kassawara. Variabilidade genética de isolados de Fusarium spp. e estudo da interação com a planta hospedeira. 2005. Tese (Doutorado em Genética e Melhoramento de Plantas) - Escola Superior de Agricultura Luiz de Queiroz, Universidade de São Paulo, Piracicaba, 2005.

MONTEIRO, A. S. Análise genomica e sequenciamento automático de rDNA em populações de Fusarium oxysporum. 2004. 75 f. Dissertação (Mestrado em Química e Biotecnologia) - Universidade Federal de Alagoas, Maceió, 2004.

MOUCHREK FILHO, V.E. Introdução à química de óleos essenciais. São Luís, 2000.

OLIVEIRA, Rosilene A. de; OLIVEIRA, Fernando F. de; SACRAMENTO, Célio Kersul. Óleos essenciais: perspectivas para o agronegócio de especiarias na Bahia. Bahia Agrícola, v.8, n. 1, nov. 2007.

OLIVEIRA, M. L. et al. Black root rot caused by Rosellinia pepo, a new disease of the clove tree in Brazil. Tropical plant pathology, vol. 33, n. 2, p. 90-95, 2008.

OLIVEIRA, R. A. et al. Constituintes químicos voláteis de especiarias ricas em eugenol.

Revista Brasileira de Farmacognosia, v. 19, n. 3, p. 771-775, 2009.

OMS. Apóia estudo com plantas medicinais. Disponível em: <http:www.drashi/fitoterapia_ oms_apoia_estudos_com_plantas medicinais. htlm>. Acesso em: 10 maio de 2012.

PEREIRA, Marcelo Cláudio et al. Inibição do desenvolvimento fúngico atraves da utilização de óleos essenciais de condimentos. Ciênc. Ciênc. agrotec. [online]. 2006, v. 30, n. 4, p. 731-738. Disponível em: <http://www.scielo. br/pdf/cagro/v30n4/v30n4a20.pdf >. Acesso em: 16 maio 2012.

RAINA, V.K. et al. Essential oil composition of Syzygium aromaticum leaf from Little Andaman, India. Flavour Fragrance Journal, v. 16, p. 334-336, 2001.

RAVEN, P. H.; EVERT, R. F.; EICHHORN, S. E. Biologia Vegetal. Rio de Janeiro: Ed. Guanabara Koogan, 2001. 906p.

SALGADO, Ana Paula Soares P. et al. Avaliação da atividade fungitóxica de óleos essenciais de folhas de eucalyptus sobre fusarium oxysporum, botrytis cinérea e bipolaris sorokiniana. Ciênc. Ciênc. agrotec., v. 27, n. 2, p. 249-254, 2003. Disponível em: <http://www.scielo.br/pdf/cagro/v27n2/ a01v27n2.pdf >. Acesso em: 16 maio 2012.

SANTOS, Luís Gustavo Martinez dos et al. Avaliação do potencial fungitóxico do óleo essencial de syzygium aromaticum (L.) Merr \& Perry (cravo-da-índia). Tecno-Lógica, Santa Cruz do Sul, v. 11, n. 1, p. 11-14, jan./dez. 2007.

SILVA-SANTOS, A. et al. A participação da indústria óleo-citrícola na balança comercial brasileira. Rev. Bras. Pl. Med. v. 8, n. 4, p. 8-14, 2006.

SILVA, S. A. et al. Atividade antimicrobiana e antiaderente in vitro do extrato de Rosmarinus officinalis Linn. sobre bactérias orais planctônicas. Rev Bras Farmacogn, n. 18, p. 236-240, 2008.

SILVESTRI, Jandimara Doninelli Fior et al. Perfil da composição química e atividades antibacteriana e antioxidante do óleo essencial do cravo-da-índia (Eugenia caryophyllata Thunb.). Rev. Ceres, v. 57, n. 5, p. 589-594, 2010. Disponível em: <http://www.ceres.ufv.br/ceres/revistas/ V57N005P05809.pdf $>$. Acesso em: 10 maio 2012.

SIMÕES, C. M. O. et al. Farmacognosia: da planta ao medicamento. Porto Alegre: UFRGS, 2007. 821p.

. Farmacognosia: da planta ao medicamento. Porto Alegre: UFRGS, 1999.

SOUSA, A. M.; WALDMAN, W. R. Especiarias. Nova Friburgo: Instituto Virtual de Estudos de Meio Ambiente e Saúde, 2009.

VICTÓRIO, Cristiane Pimentel; LAGE, Celso Luiz Salgueiro. Uso de plantas medicinais.

Revista Arquivos FOG - Saúde, Sociedade, Gestão e Meio Ambiente, v. 5, n. 1, p. 33-41, 2008. 
WENQIANG, G. et al. Comparison of essential oils of clove buds extracted with supercritical carbon dioxide and other three traditional

extraction methods. Food Chemistry, v. 101, p. 1558-1564, 2007.
WILLIANS, D. G. The chemistry of essencial oils. England: Micelle Press, 1996. 334p.

WOLFFENBUTTEL, Adriana Nunes. Óleos essenciais. Informativo CRQ-V, ano XI, n. 105, p. 6-7, nov./dez. 2007. 